\section{Diagnóstico genÉTico DISPONIBLE PARA la ENFERMedAd de Huntington en ChILE}

\section{Availability of GeNetic diagnosis of Huntington disease in Chile}

Sr. Editor: La enfermedad de Huntington es un paradigma de enfermedad neurológica hereditaria. Su prevalencia en la población general varía entre 5 a 9 por 100.000 habitantes $^{1}$. Se caracteriza por la presencia de movimientos anormales como corea, distonia, tics o parkinsonismo asociados a deterioro cognitivo y manifestaciones psiquiátricas, como depresión ${ }^{1}$. Su herencia es autonómica dominante con una penetración de $100 \%$ en la generación afectada. Grandes progresos ha habido en los últimos 10 años para entender la fisiopatología de la enfermedad y hay varios estudios en curso para intentar retrasar su avance.

En Chile desde hace muchos años fue un gran anhelo contar con el examen genético que permite confirmar la enfermedad, ya sea en el estado sintomático o presintomático. Este hecho es básico si se quiere plantear un tratamiento neuroprotector que impida el avance de esta devastadora enfermedad, a lo que apunta la investigación actual. En varios países de Latinoamérica el test está ya disponible hace tiempo como, por ejemplo, en Argentina, Perú, Brasil y Venezuela, país este último con una gran prevalencia en la zona del lago Maracaibo (700 por 100.000 habitantes), lo que permitió a investigadores norteamericanos encontrar la mutación y el gen que causa la enfermedad ${ }^{2}$

Contar con un diagnóstico preciso permitirá entre otras cosas tener una idea de la prevalencia en nuestra población, información de la cual no se dispone y que permitirá realizar programas y coberturas de acuerdo a estos datos.
En la enfermedad de Huntington el defecto genético está en el gen que codifica para la proteína huntingtin $(\mathrm{HD})^{2,3}$. Este defecto hace que la secuencia CAG se repita más de 40 veces, con una interacción anormal con otras proteínas que lleva, finalmente, por mecanismos no aclarados aún, a la muerte neuronal ${ }^{3}$.

Por lo tanto un sujeto que tiene el gen HD con 40 o más repeticiones de CAG va a desarrollar la enfermedad en algún momento de su vida y sus hijos tienen $50 \%$ de riesgo de heredar la expansión de CAG y desarrollar esta enfermedad. Cuando el gen HD tiene un número normal de repeticiones de CAG $(<27)$ no hay peligro de desarrollar la enfermedad ni de heredarlo a sus hijos. Si el gen de HD tiene 27 a 35 repeticiones de CAG el sujeto portador no está en peligro de desarrollar HD, pero, si es varón, puede tener hijos que podrían desarrollar la enfermedad. Si el sujeto tiene un gen de HD con 36 a 39 repeticiones de CAG podría o no desarrollar la enfermedad, pero sus hijos podrían desarrollar la enfermedad ${ }^{1}$.

Gracias a una iniciativa en conjunto entre médicos, investigadores básicos y familiares de la Agrupación Chilena de Huntington está accesible el test en nuestro país.

Nuestro laboratorio ha implementado un método de diagnóstico genético usado internacionalmente para la determinación del número de repeticiones del gen de HD, amplificando un fragmento de ADN que contiene las repeticiones de CAG.

Para realizar el examen se requiere de la solicitud del médico tratante $\mathrm{y}$, en los casos asintomáticos donde el fin es conocer si son portadores o no de la mutación, es necesario el apoyo y evaluación psicológica previa y posterior al test, independientemente del resultado final, para así abordar mejor las consecuencias que implica el diagnóstico ${ }^{4}$. En los niños y adolescen- 
tes no se recomienda su realización hasta que no sea una decisión tomada con criterio suficientemente formado ${ }^{4}$.

Para mayor información ver sitio web www.huntington.cl

Financiado por proyecto № 1061083.

\section{Carolina Pérez $\mathbf{P}^{1}$, Marcelo Miranda $\mathbf{C}^{2}$, Juan Segura-Aguilar ${ }^{1 .}$}

${ }^{1}$ Programa de Farmacología Molecular y Clínica, Instituto de Ciencias Biomédicas, Facultad de Medicina, Universidad de Chile, Santiago de Chile. ${ }^{2}$ Unidad de Neurología, Clínica Las Condes.

\section{REFERENCIAS}

1. Vonsattel JP, De Figlia M. Huntington's disease. J Neurop Exp Neurol 1998; 57: 369-84.

2. The Huntington's disease Collaborative research group. A novel gene containing a trinucleotide repeat that is expanded and unstable in Huntington's disease chromosomes. Cell 1993: 72: 971-93.

3. Nucifora FC Jr, Sasaki M, Peters Mf, Huang H, Cooper JK, YAMADA M ET AL. Interference by huntingtin with CBP mediated transcription leading to cellular toxicity. Science 2001: 291: 2423-8.

4. Harper P. Genetic Counseling in Huntington's disease. En Harper P. Ed: Huntington's disease. London. WB Saunders 1996: 359-94. 